\title{
Biophilic cities as a key to sustainability: a case study of Oslo
}

\begin{abstract}
Urbanisation, which has been rapidly progressing for the past few decades, is a powerful ecological factor. It changes the whole human environment and leads to many issues, e.g. air and water pollution and related physical health problems, as well as mental distress. One of the possible solutions to reduce or completely eliminate these negative effects in the long run is the concept of a biophilic city based on the idea of organic connections between people and other living creatures and their belonging to nature.

Oslo, a perfect example of biophilic city and European Green Capital, has been chosen for analysis in this paper. This research will analyse the positive effects of this concept (e.g. conservation of biological diversity) on people's well-being, as well as on the environment. Furthermore, the main goal is to determine the key principles of a biophilic city and to analyse how they can be effectively implemented in practice. Through the example of Oslo, this research will illustrate how nature can be consistently integrated into the urban infrastructure and what kind of urban development measures should be taken.
\end{abstract}

Keywords: biophilic city, sustainability, green city, sustainable city

1 Budapest Business School Faculty of International Management and Business; e-mail: yarantsevamarina@ gmail.com.

DOI: http://dx.doi.org/10.31570/Prosp 2019037. 


\section{Introduction}

Over the last few centuries our world has faced an exponential growth of the production based on an unprecedented technological development and coupled with the rapid growth of the global population. These tendencies have fundamentally changed the principle of using natural resources in order to satisfy the increasing demand of a rapidly growing population.

Urban development, which can be described as the process of emergence of the world dominated by urban values (Clark 1982), is one of the most significant consequences of these changes. The rapidly increasing spatial influence determines greatly people's worldviews and some traits of the global modern society. In this regard, two main processes of urban development should be emphasised - urban growth and urban sprawl. The first concept refers to the key importance of cities as "a concentration of population within a particular economy and society" (Bhatta 2010: 3), which can have both beneficial and adverse consequences, whereas the second refers rather to the negative impact that the rapid expansion of urban areas has on the environment and people's lives (ibid.).

In response to these severe negative consequences, which are increasingly determining our lives, a great number of people with different occupations (politicians, scientists, urban planners as well as ordinary citizens) have been looking for efficient ways that would help to minimise and eventually overcome the adverse impacts of urban growth and sprawl. One of the most comprehensive approaches was developed by Dr Timothy Beatley, a sustainable city researcher. Analysing dire consequences of the urban development in the United States, he coined the term green urbanism (Beatley 2000). His main idea is that cities leave "sizeable ecological footprints" (op. cit. 3), however, people hardly reflect any understanding of ecological constraints. Cities that exemplify green urbanism must show certain characteristics. First, they should "live within their ecological limits, [...] and acknowledge their connections with and impacts on [...] the planet" (op. cit. 6), meaning that a town or a city is no longer an antithesis of nature. On the contrary, they can function as large resilient ecosystems in which all parts are interrelated and maintain stability of the world. Moreover, dynamic interaction with nature is characterised by an increasing awareness of the natural environment, such as rivers, lakes and coastal zones, which are considered as "fullfledged neighbours".

The suggestion that people feel being part of a common living world, which reflects the idea of biophilia, was popularised in the 1980s by Harvard socio-biologist E. O. Wil- 
son. He defines the concept of biophilia as "the innate emotional affiliation of human beings to other living organisms" (Wilson 1993: 31). Timothy Beatley used Wilson's idea as a basis (Beatley 2011), having connected it to urban planning and introduced the concept of biophilic city that presupposes an intensive interaction between people and nature, but also incorporating the latter into the urban infrastructure. Thus, the principles of biophilia were expanded to include "economy and design, healing of the urban landscape and well-being" (Littke 2016: 16).

First, a key feature of biophilic urbanism underlines emotional commitment, a deep relationship with nature and therefore a genuine concern for the place of living and the environment as a whole. Consequently, the biophilic design of cities should go beyond usual parks. It implies the need to reorganise the traditional approach to construction and urban planning, as development should "increase the presence of nature" (RussoCirella 2017), which means understanding a city as a place that acknowledges global nature as an equitable part and conserves it as "shared habitat for non-human life and people" (Biophilic Cities 2012).

The purpose of this research is to analyse how efficient the concept of biophilia can be in order to minimise and, in the future, reduce to zero the negative effects of urban development. Another equally important aim of this study is to examine what actions should be taken to turn the principles of a biophilic city into reality, through the example of Oslo, European Green Capital of 2019 (European Comission 2019). There has been a remarkable progress of green development over the past few decades, in parallel with economic and technological growth. This experience of an integrated Norwegian approach could be adopted by other European cities as well, because the conditions of green and biophilic localities can also "serve to make a city more resilient in the long run, ecologically, economically and socially” (Beatley-Newman 2013: 3332).

\section{Biophilic cities as a key to sustainability}

It has already been mentioned that the concept of biophilia is offered by modern city researchers as the most effective way to minimise damage and to provide an environment of stability for human livelihood. However, it is necessary to observe the positive influence which is exerted by the biophilic urbanism on the environment and on humans as its inseparable part.

In response to the question of why it is important for the people to establish a connection with nature, Timothy Beatley claims that people need it more than they realise (Beatley 2011). By investing in green infrastructure and undertaking biophilic projects, 
states and municipalities can pursue the future development in the economic sense, as well as improve people's well-being. The effect of these green measures can be assessed directly - based on their resilience benefits (e.g. maintenance and restoration of biological diversity by establishing wildlife centres), or indirectly - as they can have some beneficial side effects (such as organising a common bike tour that is not only good for people's health, but also helps to develop stress tolerance). Let us then consider "the key pathways from biophilic urbanism to biophilic resilience" (Beatley-Newman 2013: 3333) in greater detail.

One of the most obvious potential benefits of a biophilic city is the protection of the ecosystem (such as forests, lakes, rivers or wetlands) in and around the city. There can be no doubt that these biological systems are essential for people's well-being and activities, providing food, recreational facilities and even minimising the damages caused by natural disasters. Many insightful examples were provided by Timothy Beatley in his book "Biophilic Cities: Integrating Nature into Urban Design and Planning". Let us consider just one of them.

Many regions in the United States are threatened by natural hazards, such as floods, storms, and hurricanes. In Louisiana alone, there were more than ten storms and hurricanes over the past few decades (Roth 2010). However, Beatley claims that in New Orleans for example "vulnerability to storms and flooding has been significantly increased as a result of a long history of wetlands alterations" (Beatley-Newman 2013: 3333). Those natural disasters caused billions of dollars in damage and the death of thousands of people. However, since the start of a coastal restoration project in 2008, approximately 1000 acres of wetlands have been recreated (Roth 2010). As a result, these measures helped to avoid major hurricanes in New Orleans. In this regard, it could be concluded that the preservation or, in this case, the recovery of the wetlands system around the city is a key factor for the sustainability of the whole region.

Another potential benefit of a biophilic city is that it can reduce the negative impact living in big cities has on our psyche. The rapid urban growth and sprawl has fuelled the extensive construction of houses and other kinds of infrastructure, along with the reduction of green areas, causing psychic strain and different kinds of mental health problems, such as depression or neurosis (World Health Organization 2003).

However, numerous studies showed that outdoor leisure activities can significantly reduce stress and help to regain strength (Gullone 2000). For example, American scientists conducted a research concerning the restoration of the environment and its impact on human well-being (Hartig-Mang-Evans 1991). Their experiment wanted to find out how nature can both reduce stress and induce cognitive performance. They 
investigated three groups of people and randomly assigned the participants to take part in different types of activities. The first group had to walk for 40 minutes in a green urban area with a lot of plants and trees and surrounded by natural sounds. The second group also walked for 40 minutes, but in a typically urban area - safe, attractive, but almost without any presence of greenery. The third group was just asked to read or listen to music for the same amount of time. Researchers found that those who spent time walking in the nature behaved in a more positive way than those who did not have any contact with a natural environment. The former group also expressed a greater willingness to work and performed cognitive tasks better.

The internal aspiration of the unity with nature brings people belonging to different age, gender, marital status and professional activity together. What brings all these people together is the fact that in times of stress they need tranquillity and emotional recharge that nature is likely to provide. Thus, as the world economic crisis hit in 2008, people from various parts of the world started to walk in parks and recreational zones at a notably higher rate than before (Trust for Public Land 2009). This could lead to the conclusion that in conditions of (especially financial) fragility urban dwellers felt the urge to go to places which they could consider as an island of stability. "A city with few such green spaces will be less prepared, less able to provide such emotional comfort" (Beatley-Newman 2013: 3337).

A biophilic city can ensure a healthier and more comfortable life in many other ways as well. One study found that living far from green areas can be a factor behind the deterioration of physical health (Hinds-Sparks 2011). One of the main negative consequences of uncontrollable urbanisation is air pollution. According to the statistics of the World Health Organisation, "9 out of 10 people now breathe polluted air, which kills 7 million people every year" (World Health Organization 2018). However, these frightening figures can be improved through effective urban planning, infrastructure development and other technologies, such as energy-saving and renewable energy solutions.

A wide range of impacts, which can be observed within the concept of a biophilic city (preservation of ecosystems, $\mathrm{CO}_{2}$ reduction, improving water and air quality etc.), are beneficial (or more specifically, redemptive) not only for our planet, but first and foremost it impacts inhabitants' lives, their well-being, economic prosperity and social advance, their safety and the full development of their human potential in a positive way. Based on these considerations, people should use their economic and scientific resources to save the natural features in urban environment. 


\section{Oslo and the integration of biophilic ideas}

In this final part, it will be shown through the example of Oslo how nature can be successfully integrated into the urban infrastructure. As previously stated, Oslo has officially become the European Green Capital of 2019 (European Comission 2019). However, the history of sustainable development in Norway is a relatively long one, partly due to the geographical position of Norway and Oslo in particular. The capital of Norway is surrounded by a ford and vast woods, these latter covering two thirds of the city's surface. These forests are also protected by the government. Now let's take a closer look at the extensive network of green projects fostering sustainable development.

One of the main focuses of environmental policy in Oslo is emission reduction through transport network development as well as creating a zero-emissions transport system (European Comission 2019). As Figure 1 shows, public and private transport is the sector with the largest share of emissions.

Figure 1. Oslo's emissions by source in 2016

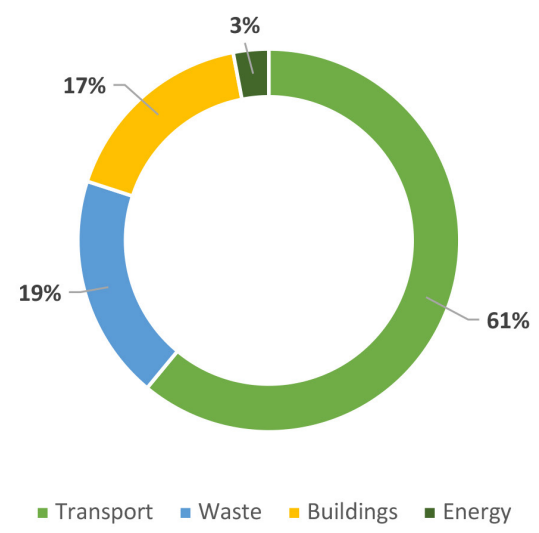

Source: Carbon Neutral Cities Alliance (2018)

For instance, " $56 \%$ of all public transport journeys are powered by renewably energy on zero-emissions trams, train and metro" (European Commission 2019). In addition, the state encourages citizens to drive electric cars. Oslo has even become the "electric vehicle capital of the world": $30 \%$ of all vehicles sold nowadays are electric (ibid). "Car free city", a municipal project, is also aimed to reduce exhaust emission and change approximately $1.3 \mathrm{~km}^{2}$ into a better urban environment by 2019 (The City of Oslo 2019). 
To a certain degree, people tend to quit driving their own cars due to the high cost of parking passes, the cost of which is $56 \%$ of the average cost of daily food (Kodukula et al. 2018). In order to significantly reduce car traffic, the urban governance decided to increase the number of public transport journeys by 50\% compared to its 2007 value (European Comission 2019). Also, approximately 800 bicycle paths have been created to connect different parts of Oslo (UN Environment 2018). These and many other measures are considered as effective. By 2020, the city aims to cut $\mathrm{CO}_{2}$ emissions by almost 50\% and to become carbon neutral by 2050 (Municipality of Oslo 2018). As a result of these measures, Oslo could not only achieve a significant improvement in the areas of air quality and the well-being of its inhabitants, but has also developed new advanced alternative fuel technologies.

Another major objective for Oslo is to integrate the natural environment into the urban setting. First, the local government creates a network of paths to connect urban and green areas, so citizens can walk and ride their bikes undisturbed. The city governance has implemented a bike-sharing system, so that city-dwellers and visitors can easily pick up a bicycle at one of the 200 stations (UN Environment 2018). As detailed above, one of the most important objectives for the municipality is to keep the population physically active. Thus, there is " $28 \%$ walking modal share and $7 \%$ cycling share" in Oslo (Kodukula et al. 2018: 51). The city "also proudly announces that about $95 \%$ of its residents have access to green space within $300 \mathrm{~m}$ of their home" (ibid).

These local policies are aimed at making citizens an integral part of the process. However, it still needs further improvements, for instance, by developing infrastructure, increasing the accessibility of public transport, as well as finding out how to minimise the impact of the Norwegian cold and humid weather on the usability and convenience of sustainable projects.

\section{Conclusion}

Oslo is a good example of how to turn the idea of biophilic urbanism into reality, which is most clearly manifested through the creation of urban ecosystems that are as close to the natural ones as possible. The implicit objective of this paper was to convince the readers that this positive experience of urban planning could be used and developed in other countries as well. Clear benefits of this approach should be able to encourage more researches in order to make strategies more effective and also to adopt them to other cities with different climate conditions. 


\section{References}

Beatley, T. (2000). Green urbanism: learning from European Cities. Washington, D.C.: Island Press.

Beatley, T. (2011). Biophilic Cities: Integrating Nature into Urban Design and Planning. Washington, D.C.: Island Press.

Beatley, T. - Newman, P. (2013). Biophilic Cities Are Sustainable, Resilient Cities. Sustainability, August 5, 3328-3345.

Bhatta, B. (2010). Analysis of Urban Growth and Sprawl from Remote Sensing Data. Berlin, Heidelberg: Springer.

Biophilic Cities (2012). Our vision. Connecting Cities and Nature. https://www.biophiliccities.org/our-vision. Retrieved 29.03.2019.

Carbon Neutral Cities Alliance (2018). Oslo. Norway. https://carbonneutralcities.org/ cities/oslo/. Retrieved on 19.04.2019.

Clark, D. (1982). Urban Geography: An Introductory Guide. London: Taylor \& Francis. European Commission (2019). 2019 - Oslo. http://ec.europa.eu/environment/europeangreencapital/winning-cities/2019-oslo/. Retrieved on 30.03.2019.

Gullone, E. (2000). The Biophilia Hypothesis and Life in the 21st Century: Increasing Mental Health or Increasing Pathology? Journal of Happiness Studies, (1)3, 293-321. Hartig, T. - Mang, M. - Evans, G. (1991). Restorative effects of natural environment. Environment and Behavior, (23)1, 3-26.

Hinds, J. - Sparks, P. (2011). The Affective Quality of Human-Natural Environment Relationships. Evolutionary Psychology, (9)3, 451-469.

Kodukula, S. - Rudolph, F. - Kansen, U. - Amon, E. (2018). Living. Moving. Breathing. Ranking of European Cities in Sustainable Transport. Hamburg: Greenpeace e.V.

Littke, H. (2016). Becoming biophilic: Challenges and opportunities for biophilic urbanism in urban planning policy. Emerald Insight, (5)1, 15-24.

Marc, L. - Roe, P.G. (2012). Green Oslo: Visions, Planning, and Discourse. New York: Routledge.

Municipality of Oslo. (2018). Climate budget 2018. Oslo: Climate Agency.

Roth, D. (2010). Louisiana Hurricane History. https://www.weather.gov/media/lch/ events/lahurricanehistory.pdf. Retrieved on 30.03.2019.

Russo, A. - Cirella, G. (2017). Biophilic Cities: Planning for Sustainable and Smart Urban Environments. In Aijaz, R. (ed.): Smart Cities Movement in BRICS, 153-157. New Delhi: Vinset Advertising. 
The City Of Oslo (2019). Car free city life in Oslo. https://www.oslo.kommune.no/english/politics-and-administration/green-oslo/best-practices/car-free-city/. Retrieved on 20.04.2019.

Trust for Public Land (2009). Parks and Playground Use Up in Down Economy. San Francisco, CA: TPL.

UN Environment (2018). Oslo takes bold steps to reduce air pollution, improve livability. https://www.unenvironment.org/news-and-stories/story/oslo-takes-bold-stepsreduce-air-pollution-improve-livability. Retrieved on 30.03.2019.

Wilson, E. (1993). Biophilia and the conservation ethic. In Kellert, S. - Wilson, E. (eds.): The Biophilia Hypothesis. Cambridge: Harvard University Press.

World Health Organization (2003). The mental health context. Geneva: World Health Organization.

World Health Organization (2018). How air pollution is destroying our health. https:// www.who.int/air-pollution/news-and-events/how-air-pollution-is-destroying-ourhealth. Retrieved on 12.04.2019. 